\title{
A Simulation of the Effects of Varying Repetition Rate and Pulse Width of Nanosecond Discharges on Premixed Lean Methane-Air Combustion
}

\author{
Moon Soo Bak and Mark A. Cappelli \\ Mechanical Engineering Department, Stanford University, Stanford, CA 94305-3032, USA \\ Correspondence should be addressed to Moon Soo Bak, moonsoo@stanford.edu \\ Received 11 May 2012; Accepted 17 September 2012 \\ Academic Editor: Nickolay Aleksandrov
}

Copyright ( $) 2012$ M. S. Bak and M. A. Cappelli. This is an open access article distributed under the Creative Commons Attribution License, which permits unrestricted use, distribution, and reproduction in any medium, provided the original work is properly cited.

\begin{abstract}
Two-dimensional kinetic simulation has been carried out to investigate the effects of repetition rate and pulse width of nanosecond repetitively pulsed discharges on stabilizing premixed lean methane-air combustion. The repetition rate and pulse width are varied from $10 \mathrm{kHz}$ to $50 \mathrm{kHz}$ and from $9 \mathrm{~ns}$ to $2 \mathrm{~ns}$ while the total power is kept constant. The lower repetition rates provide larger amounts of radicals such as $\mathrm{O}, \mathrm{H}$, and $\mathrm{OH}$. However, the effect on stabilization is found to be the same for all of the tested repetition rates. The shorter pulse width is found to favor the production of species in higher electronic states, but the varying effects on stabilization are also found to be small. Our results indicate that the total deposited power is the critical element that determines the extent of stabilization over this range of discharge properties studied.
\end{abstract}

\section{Introduction}

Nanosecond repetitively pulsed discharges have been studied as possible sources to stabilize combustion at fuel-lean and blow-off conditions [1]. The stabilization has been attributed to the significant radical production and gas heating within the discharges $[1,2]$. The relative importance of these two outcomes on the stabilization has been debated. However, the effects of these two discharge outcomes on stabilization are difficult to separate because the two mechanisms stem from the same process of collisional quenching of electronically excited species (produced by direct electron impacts) [2, 3]. Also, the influence of radicals such as $\mathrm{O}$ and $\mathrm{H}$ is more pronounced at high gas temperature where the branching and propagation reactions can compete with the termination reactions. It is notable that Pilla et al. [4] reported that they were able to stabilize combustion when the discharge is at filamentary mode (e.g., streamers) rather than at glow mode. Deminsky et al. [5] also reported that an acceleration of the ignition process is seen in premixed supersonic flows with filamentary discharge modes. This suggests that the gas heating that is often more pronounced in the filamentary mode is necessary for significant radical production and that the elevated gas temperature results in the persistence of radicals during the time between pulses.

A few tens of microjoule of energy per pulse, tens of kilohertz repetition rates, and a few kilovolt peak voltages are typical operation conditions of nanosecond repetitive discharges used in combustion stabilization. Under these conditions, the average electron number density that can be sustained is about $10^{11} \mathrm{~cm}^{-3}$ peaking as high as $10^{15} \mathrm{~cm}^{-3}$ with a lower power budget compared to other types of discharges [6]. There have been several studies carried out of the kinetics responsible for plasma-assisted stabilization of combustion [1], but to our knowledge, there are few, if any, experimental studies investigating the effect of repetition rate and pulse width (for this type of discharge) on stabilization. This is because the power that is deposited into the discharge region is difficult to control and accurately characterized.

In this paper, we examine the effect of variations in the repetition rate and the pulse width on premixed methaneair combustion using a 2-D kinetic simulation. In these simulations we set the total power to be constant and vary the repetition rate between $10 \mathrm{kHz}$ and $50 \mathrm{kHz}$ and the pulse 


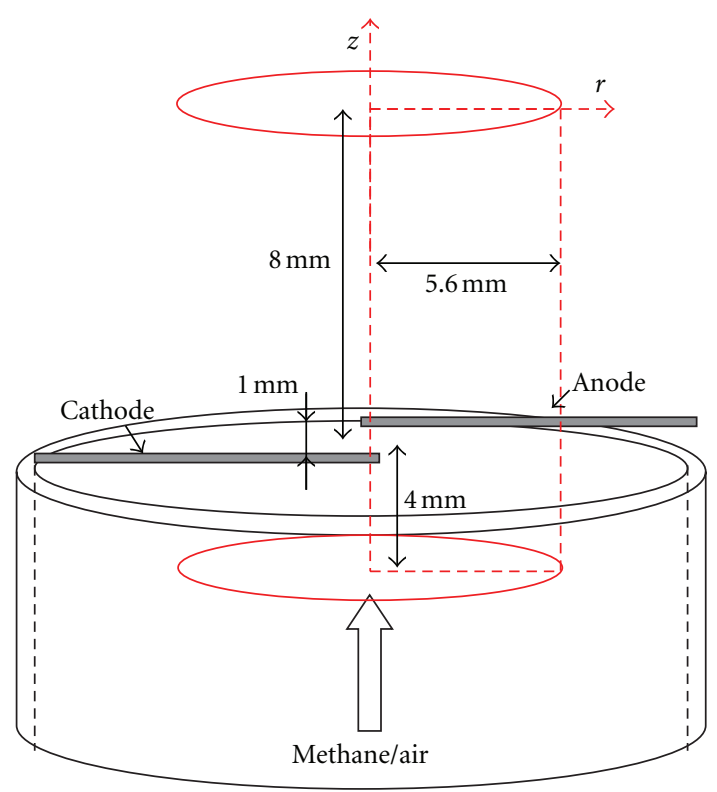

FIGURE 1: 2-D kinetic simulation domain.

width from $9 \mathrm{~ns}$ to $2 \mathrm{~ns}$. In this way, the primary variables are the energy per pulse and therefore the amount of produced radicals and their ability to survive between pulses. The kinetics within the discharge region and the quasi-steady contours between the cases are compared in detail.

\section{Simulation Description}

The simulated domain, marked as a red-dotted box, is shown in Figure 1. Axisymmetric coordinates are used in this simulation, and the size of the domain is set to $12 \mathrm{~mm}$ in height ( $z$-axis) and $5.6 \mathrm{~mm}$ in radius ( $r$-axis), spanning the discharge region. The center of the discharge region is located $4 \mathrm{~mm}$ above the lower computational boundary, on the axis, and has size of $1 \mathrm{~mm}$ in height and $0.35 \mathrm{~mm}$ in diameter. This diameter is chosen to agree with the measured diameter in the similar experiments of Pai et al. [7]. A uniform grid spacing $(0.333 \mathrm{~mm}$ along the $z$-axis and $0.175 \mathrm{~mm}$ along the $r$-axis) is used in these simulations. Species considered include ground and electronic excited states of $\mathrm{N}_{2}(\mathrm{X}, \mathrm{A}$, $\mathrm{B}, \mathrm{a}^{\prime}, \mathrm{C}$ ), the ground electronic states of $\mathrm{O}_{2}, \mathrm{~N}_{2}{ }^{+}, \mathrm{O}_{2}{ }^{+}, \mathrm{O}$, $\mathrm{CH}_{4}, \mathrm{H}_{2} \mathrm{O}, \mathrm{CO}_{2}, \mathrm{CH}_{4}{ }^{+}, \mathrm{H}_{2} \mathrm{O}^{+}, \mathrm{CO}_{2}{ }^{+}$, and free electrons (e), amongst others. These species are added to the reduced reaction mechanism, DRM19 [8], that is often used for simulating methane/air combustion. DRM19 has been tested against the more detailed GRI-Mech mechanism [9] for computing ignition delay times and laminar flame speeds. Thermodynamic properties for neutral species are calculated based on the use of NASA polynomials as tabulated in the GRI-Mech package. The thermodynamic properties for electrons and ions are taken from Burcat [10]. Reactions considered are electron-impact excitation and ionization of $\mathrm{N}_{2}$, electron-impact dissociation and ionization of $\mathrm{O}_{2}$ and $\mathrm{CH}_{4}$, electron-impact ionization of $\mathrm{H}_{2} \mathrm{O}$ and $\mathrm{CO}_{2}$, ion conversion, recombination of electron and positive ions, quenching of electronically excited nitrogen $\left(\mathrm{N}_{2}{ }^{*}\right)$ by $\mathrm{N}_{2}$, dissociative quenching of $\mathrm{N}_{2}{ }^{*}$ by $\mathrm{O}_{2}$ and $\mathrm{CH}_{4}$, and chemical transformation of neutral species typical in methane/air combustion reaction mechanisms. The reactions pertinent to the plasma kinetics and associated rates are provided in our previous paper [2]. Rate coefficients for reactions between neutral species and ions are adapted from previous literature, whereas those for reactions involving electrons are calculated as functions of reduced electric field $(E / n)$ based on the solution of the Boltzmann equation, which is facilitated using the commercial software, BOLSIG+ [11]. Such an approach is necessary since the reactions are coupled to the electron energy distribution function. It is noteworthy that only elastic and inelastic cross-sections associated with the major species $\mathrm{N}_{2}, \mathrm{O}_{2}, \mathrm{CH}_{4}, \mathrm{H}_{2} \mathrm{O}$, and $\mathrm{CO}_{2}$ are considered in establishing the electron energy distribution. The species conservation equation used in our simulations has the form

$$
\begin{aligned}
& \frac{\partial n_{j}}{\partial t} \\
& =\sum_{\text {reactions }}\left(v_{j}^{\prime}-v_{j}\right)\left[k_{f}\left(\frac{E}{n_{\mathrm{tot}}} \text { or } T_{e} \text { or } T_{\mathrm{gas}}\right)\right. \\
& \left.\quad \times \prod_{i} n_{\mathrm{reac}, i}^{v_{i}}-k_{b} \prod_{i} n_{\mathrm{prod}, i}^{v_{i}^{\prime}}\right] \\
& -\nabla \cdot\left(n_{j} V_{D, j}\right)-V_{\mathrm{adv}}^{*} \frac{\partial n_{j}}{\partial z}
\end{aligned}
$$

with

$$
\sum_{i} v_{i} n_{\mathrm{reac}, i} \underset{k_{b}}{\stackrel{k_{f}}{\rightleftarrows}} \sum_{i} v_{i}^{\prime} n_{\mathrm{prod}, i}
$$

The species equation is solved simultaneously with the energy equation,

$$
\begin{aligned}
& \frac{\partial T_{\text {gas }}}{\partial t} \\
& =\frac{1}{\sum_{\text {species } j} c_{v, j} n_{j}} \\
& \times\left[e n_{e} \mu_{e} E^{2}+\sum_{\text {species } j}\left\{-\frac{\partial\left(h_{f, j} n_{j}\right)}{\partial t}-\nabla \cdot\left(h_{\text {sens }, j} n_{j} V_{D, j}\right)\right.\right. \\
& \left.\left.\quad-V_{\text {adv }}^{*} \frac{\partial\left(h_{\text {sens }, j} n_{j}\right)}{\partial z}\right\}+\nabla \cdot\left(\lambda \nabla T_{\text {gas }}\right)\right],
\end{aligned}
$$

to compute the species number densities and gas temperature at each grid point. The species diffusion velocity $V_{D, j}$ is composed of the diffusion-induced convection velocity $V_{c}$, the ordinary diffusion velocity, and the thermal diffusion velocity, the latter of which is accounted for light species only, having molecular weight less than five:

$$
V_{D, j}=V_{c}-D_{j m} \frac{\nabla X_{j}}{X_{j}}+\frac{D_{j m} \Theta_{j m}}{X_{j}} \frac{\nabla T_{\mathrm{gas}}}{T_{\mathrm{gas}}} .
$$


Here, $V_{c}$ is determined to satisfy the condition

$$
\nabla \cdot\left(\sum_{\text {species }, j} n_{j} V_{D, j}\right)=0 .
$$

In the above equations, $n_{j}, X_{j}$, and $v_{j}$ are the number density, mole fraction, and stoichiometric coefficient of species $j$, $k_{f}$ and $k_{b}$ are the forward and reverse rate coefficients, $T_{e}$ and $T_{\text {gas }}$ are the electron and gas temperatures, $D_{j m}$ is the mixture average diffusion coefficient of species $j, \Theta_{j m}$ is the thermal diffusion ratio of species $j$, and $V_{\mathrm{adv}}^{*}$ is the local advection velocity, which is scaled as $T_{\text {gas }} / T_{\text {gas }, i}\left(T_{\text {gas }, i}\right.$ is the initial inlet gas temperature) assuming negligible radial velocity and constant pressure, to account for the flow acceleration caused by heat release during combustion. We assume that electrons and ions exist only in the discharge region and that the binary diffusion coefficients for electronically excited $\mathrm{N}_{2}$ are equal to those of the ground state $\mathrm{N}_{2}$. In the energy equation, $\mu_{e}$ is the electron mobility (a function of $E / n$ ), $c_{v, j}$ is the heat capacities at constant volume of species $j, h_{f, j}$ and $h_{\text {sens, } j}$ are the formation and sensible enthalpies of species $j$, and $\lambda$ is the mixture-averaged thermal conductivity. The mixture diffusion coefficient of species $j$, thermal diffusion ratio of species $j$, and mixture-averaged thermal conductivity are computed at each grid points according to (6), that is,

$$
\begin{gathered}
D_{j m}=\frac{1-Y_{j}}{\sum_{k \neq j} X_{k} / D_{k j}}, \\
\Theta_{j}=\sum_{k \neq j} \theta_{j k}, \\
\lambda=\frac{1}{2}\left(\sum_{j} X_{j} \lambda_{j}+\frac{1}{\sum_{j} X_{j} / \lambda_{j}}\right),
\end{gathered}
$$

where $X_{j}$ and $Y_{j}$ are the mole and mass fractions of species $j$, respectively, $D_{k j}$ is the binary diffusion coefficient between species $k$ and $j, \theta_{j k}$ is the binary thermal diffusion ratio for species $j$ into species $k$, and $\lambda_{j}$ is the pure thermal conductivity of species $j$.

In solving the system of partial differential equations, the diffusion processes (species and thermal conduction) are discretized by a central difference scheme, and the convection and advection processes (species and enthalpy) are discretized by an upwind scheme. The system of ordinary differential equations is then solved implicitly for each (adaptive) time step based on a backward difference formula (BDF). In the computations, the domain is divided into smaller subdomains, which are allocated to separate processes. These processes are computed in parallel, synchronizing their boundary values via the message passing interface, MPI. Sundials CVODE [12] with MPI support is used as a solver and Open MPI [13] is used for MPI-2 standard implementation. Each temporal solution is computed iteratively using the Generalized Minimal Residual method (GMRES) [14]. A Dirichlet condition is used for the lower domain boundary, whereas Neumann conditions are used for the sides and top of the computational boundary.
A Gaussian-shaped (in time) reduced electric field with given full-width half maximum is applied at the discharge region. The reduced electric field is varied to provide the total power of $0.4323 \mathrm{~W}$ while varying the repetition rate and the pulse width. The methane-air equivalence ratio is set to be 0.45 , conditions at which the flame is not self-sustaining and the combustion that is initiated at the discharge region quenches at downstream flow locations. This low value is deliberately chosen; otherwise self-sustained combustion makes it difficult to resolve the effect of the discharge. The initial advection speed is $42.5 \mathrm{~cm} / \mathrm{s}$. The initial inlet gas temperature and pressure are set to $296 \mathrm{~K}$ and $1 \mathrm{~atm}$, respectively.

\section{Simulation Results}

3.1. Results for Repetition Rates Ranging between $10 \mathrm{kHz}$ and $50 \mathrm{kHz}$. Simulations were carried out for different repetition rates ranging from $10 \mathrm{kHz}$ to $50 \mathrm{kHz}$, under conditions of constant average power. Under these constraints, the energy per pulse is higher for the lower repetition rates. The discharge pulse energies are $43 \mu \mathrm{J}, 22 \mu \mathrm{J}, 14 \mu \mathrm{J}, 11 \mu \mathrm{J}$, and $9 \mu \mathrm{J}$ for $10 \mathrm{kHz}, 20 \mathrm{kHz}, 30 \mathrm{kHz}, 40 \mathrm{kHz}$, and $50 \mathrm{kHz}$, respectively. The corresponding effective reduced electric fields are determined to be $345 \mathrm{Td}, 335 \mathrm{Td}, 328 \mathrm{Td}, 323 \mathrm{Td}$, and $318 \mathrm{Td}$. The kinetics within the discharge region is shown in Figure 2. Because of the higher electric fields for the lower repetition rates, the electron number density (Figure 2(b)) peaks at higher values and the population of excited electronic states of $\mathrm{N}_{2}$ (Figure 2(a)) are significantly larger. As a result, the gas temperature rises (Figure 2(c)) and the produced amount of radicals such as $\mathrm{O}, \mathrm{H}$, and $\mathrm{OH}$ (Figure $2(\mathrm{~d})$ ) are also significantly greater for the low repetition rates. This larger amount of the produced radicals after the pulse converts $\mathrm{CH}_{4}$ further to $\mathrm{CO}$ and $\mathrm{H}_{2}$, and finally to $\mathrm{CO}_{2}$ and $\mathrm{H}_{2} \mathrm{O}$ (Figures 2(e) and 2(f)). It is noteworthy that with this type of discharge the methane concentration remains low within the discharge region after the very first discharge pulse because the first discharge ignites the methane-air mixture and the repetition timescales tested are shorter than the times for species diffusion and advection. Although the lower repetition rates provide for higher values for the temperature and radical concentrations, their quasi-steady state levels are found to be lower because of the longer time between pulses for thermal conduction, species diffusion, and radical recombination processes. According to these simulations, the kinetic evolution is found to be more drastic for the lower repetition rates.

The quasi-steady state contours of the major and minor combustion species for different repetition rates between $10 \mathrm{kHz}$ and $50 \mathrm{kHz}$ are shown in Figures 3 and 4, respectively. The contours for $\mathrm{CH}_{4}, \mathrm{CO}_{2}, \mathrm{H}_{2} \mathrm{O}, \mathrm{CO}, \mathrm{H}_{2}$, and $\mathrm{O}$ correspond to Figures 3(a), 3(b), and 3(c) and Figures 4(a), 4(b), and $4(\mathrm{c})$, respectively. Interestingly, in spite of their different quasi-steady state values and degree of temporal evolutions for the gas temperature and the radicals, the results for these cases are almost exactly the same. Our results indicate that, for this range of repetition rate and average power, the discharge is able to maintain a sufficiently high level of 

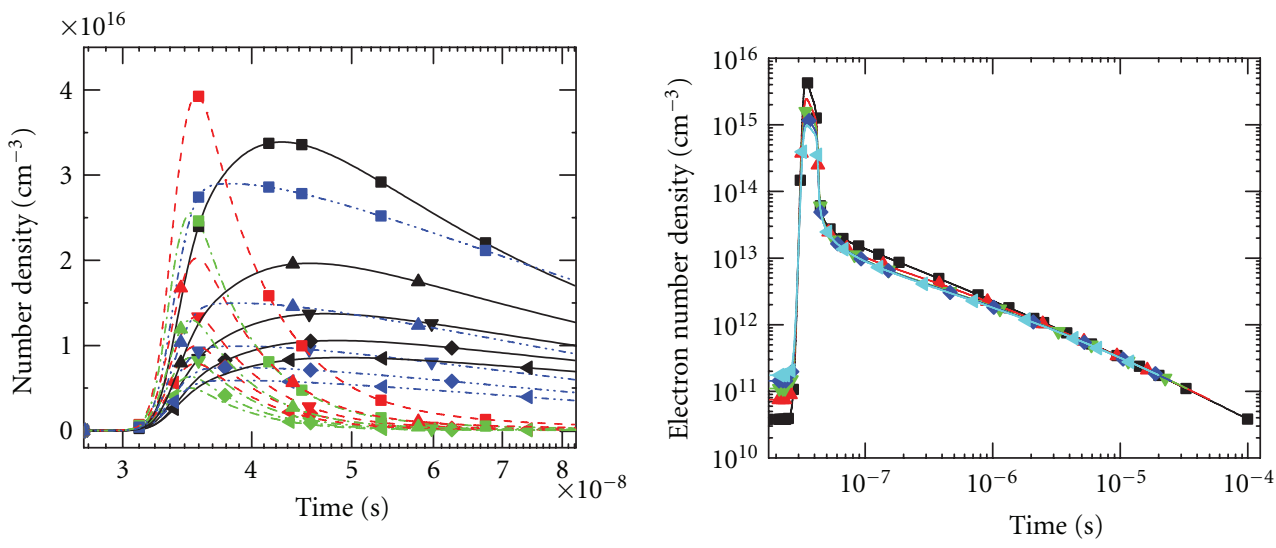

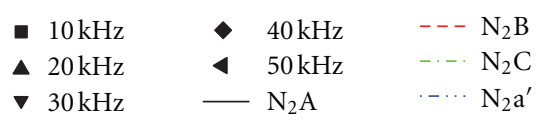

(a)
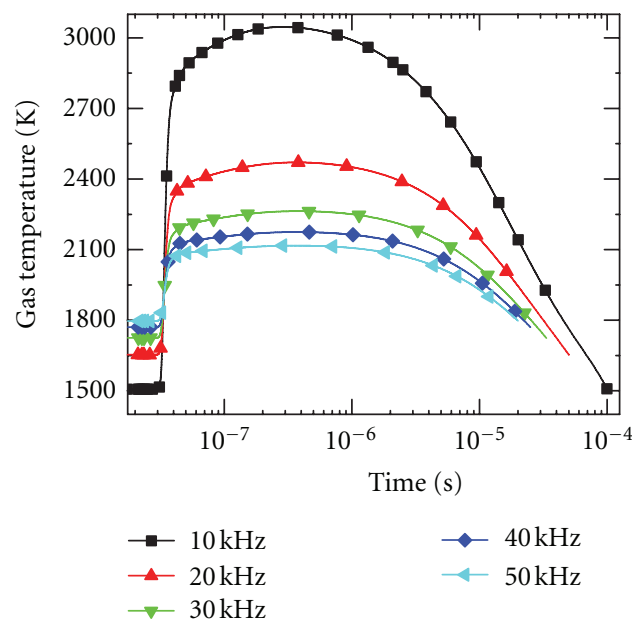

(c)

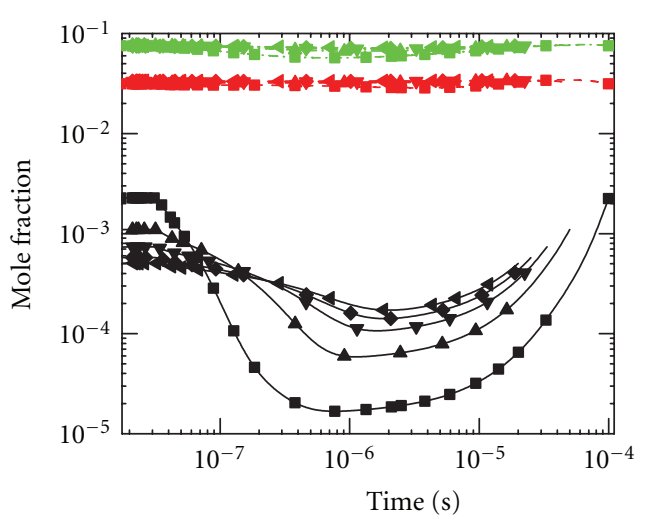

- $10 \mathrm{kHz}$

- $20 \mathrm{kHz}$

- $30 \mathrm{kHz}$

- $40 \mathrm{kHz}$

$$
\begin{aligned}
& 40 \mathrm{kHz} \\
& -\mathrm{CH}_{4} \\
& --\mathrm{CO}_{2} \\
& -. . \mathrm{H}_{2} \mathrm{O}
\end{aligned}
$$

(e)

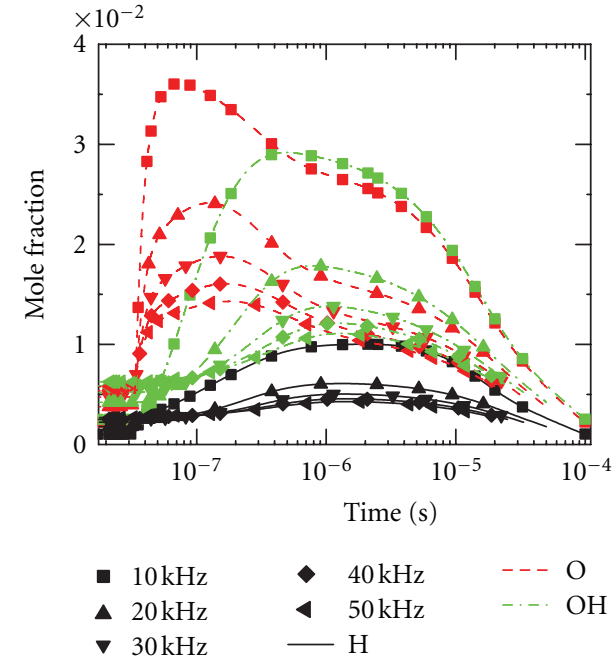

(d)

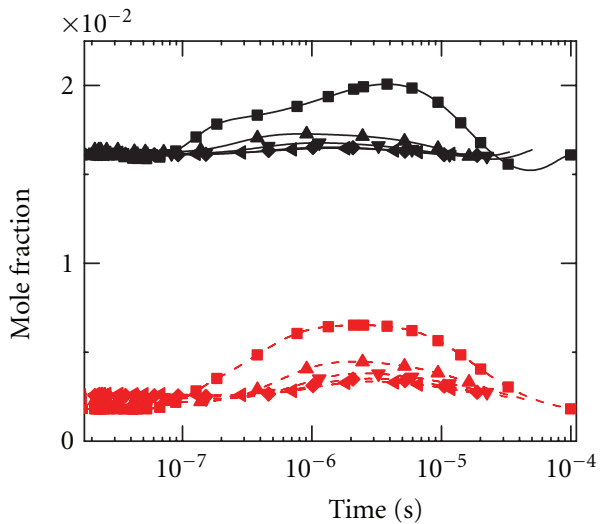

- $10 \mathrm{kHz}$
- $20 \mathrm{kHz}$
- $30 \mathrm{kHz}$
- $40 \mathrm{kHz}$

$450 \mathrm{kHz}$

$-\mathrm{CO}$

- - $\mathrm{H}_{2}$

(f)

Figure 2: Kinetic evolution of (a) excited electronic states of $\mathrm{N}_{2}\left(\mathrm{~A}, \mathrm{~B}, \mathrm{C}, \mathrm{a}^{\prime}\right)$, (b) electron, (c) gas temperature, (d) radicals $(\mathrm{O}, \mathrm{H}$, and $\mathrm{OH}$ ), (e) combustion major species $\left(\mathrm{CH}_{4}, \mathrm{CO}_{2}\right.$, and $\left.\mathrm{H}_{2} \mathrm{O}\right)$, and (f) minor species $\left(\mathrm{H}_{2}\right.$ and $\left.\mathrm{CO}\right)$ within the discharge region during a single period when the pulse width is $9 \mathrm{~ns}$ and the repetition rates are $10 \mathrm{kHz}, 20 \mathrm{kHz}, 30 \mathrm{kHz}, 40 \mathrm{kHz}$, and $50 \mathrm{kHz}$. 

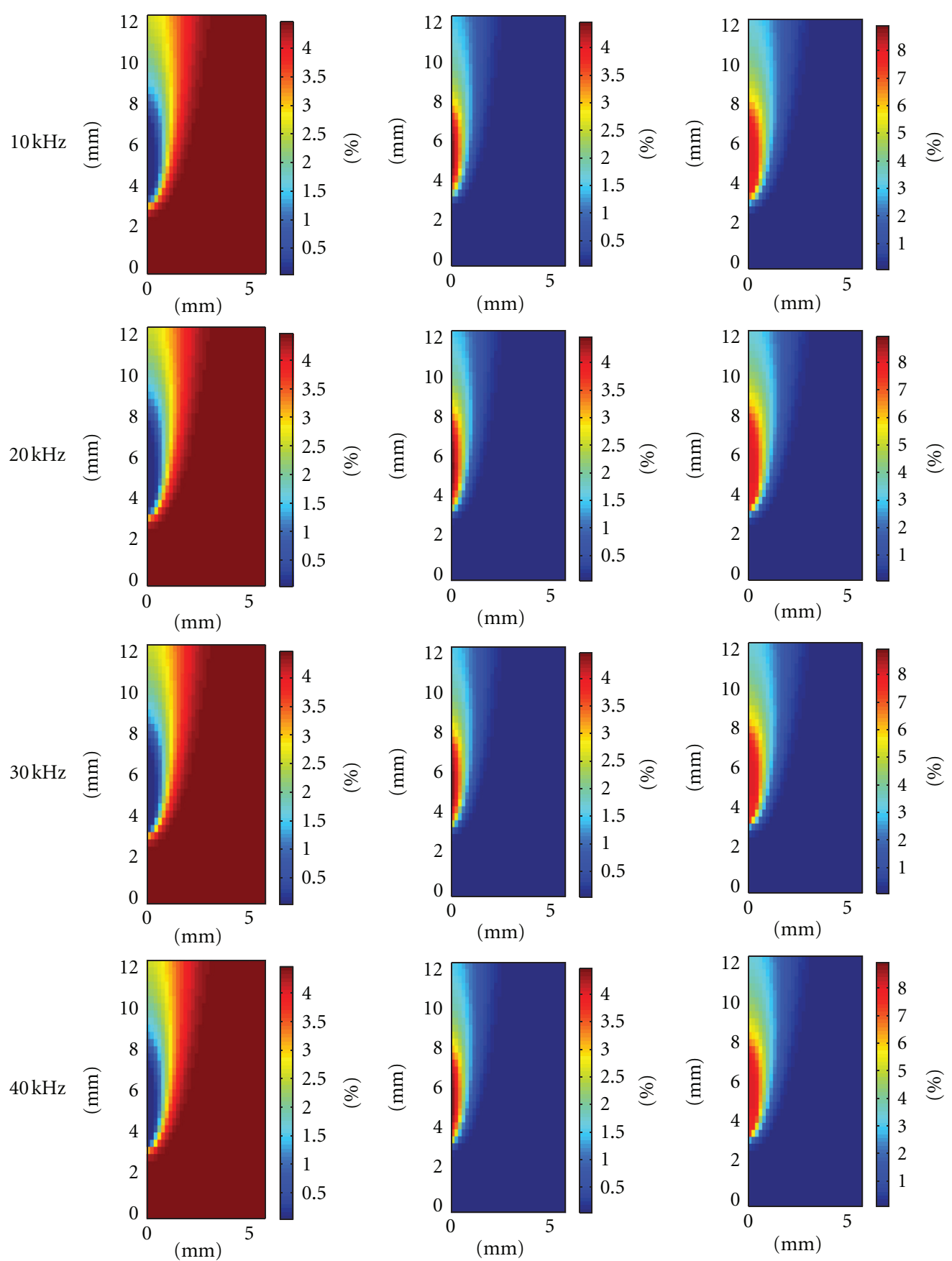

(mm)

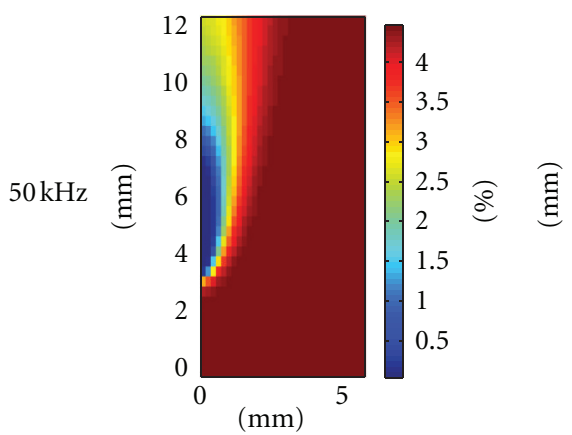

(a) $\mathrm{CH}_{4}$
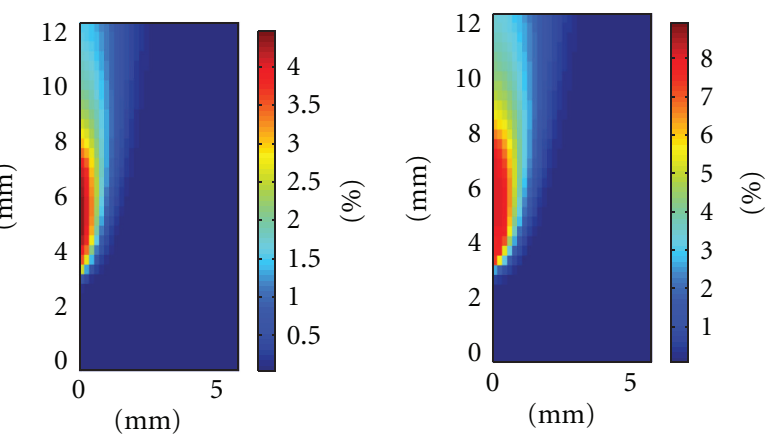

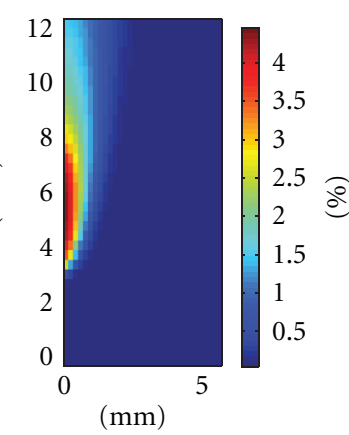

(b) $\mathrm{CO}_{2}$

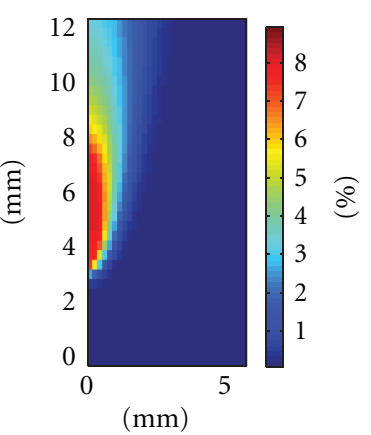

(c) $\mathrm{H}_{2} \mathrm{O}$

FIGURE 3: Quasi-steady state spatial distribution of (a) $\mathrm{CH}_{4}$, (b) $\mathrm{CO}_{2}$, and (c) $\mathrm{H}_{2} \mathrm{O}$ for different repetition rates of $10 \mathrm{kHz}, 20 \mathrm{kHz}, 30 \mathrm{kHz}$, $40 \mathrm{kHz}$, and $50 \mathrm{kHz}$ at $9 \mathrm{~ns}$ pulse width. 

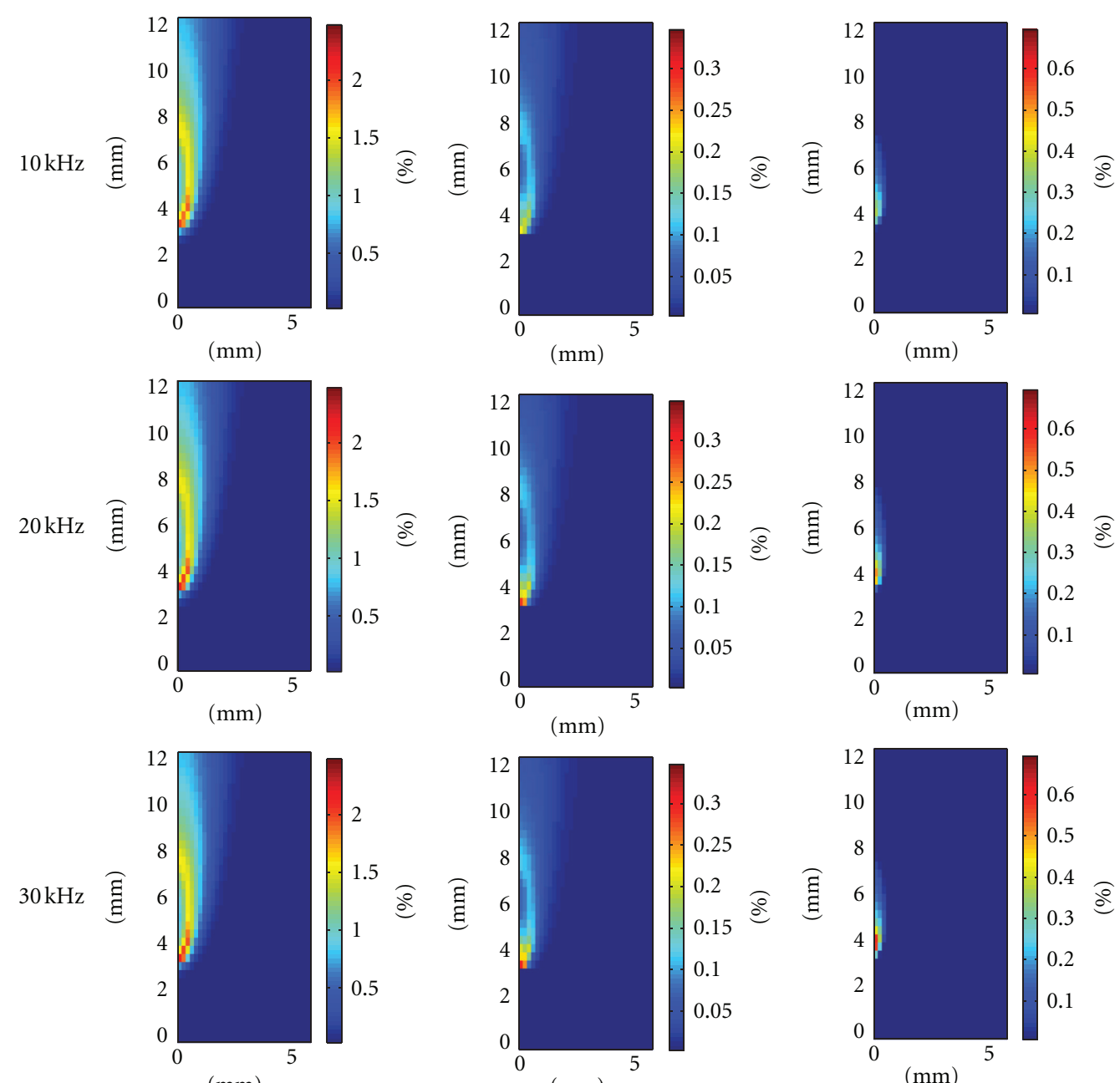

$(\mathrm{mm})$
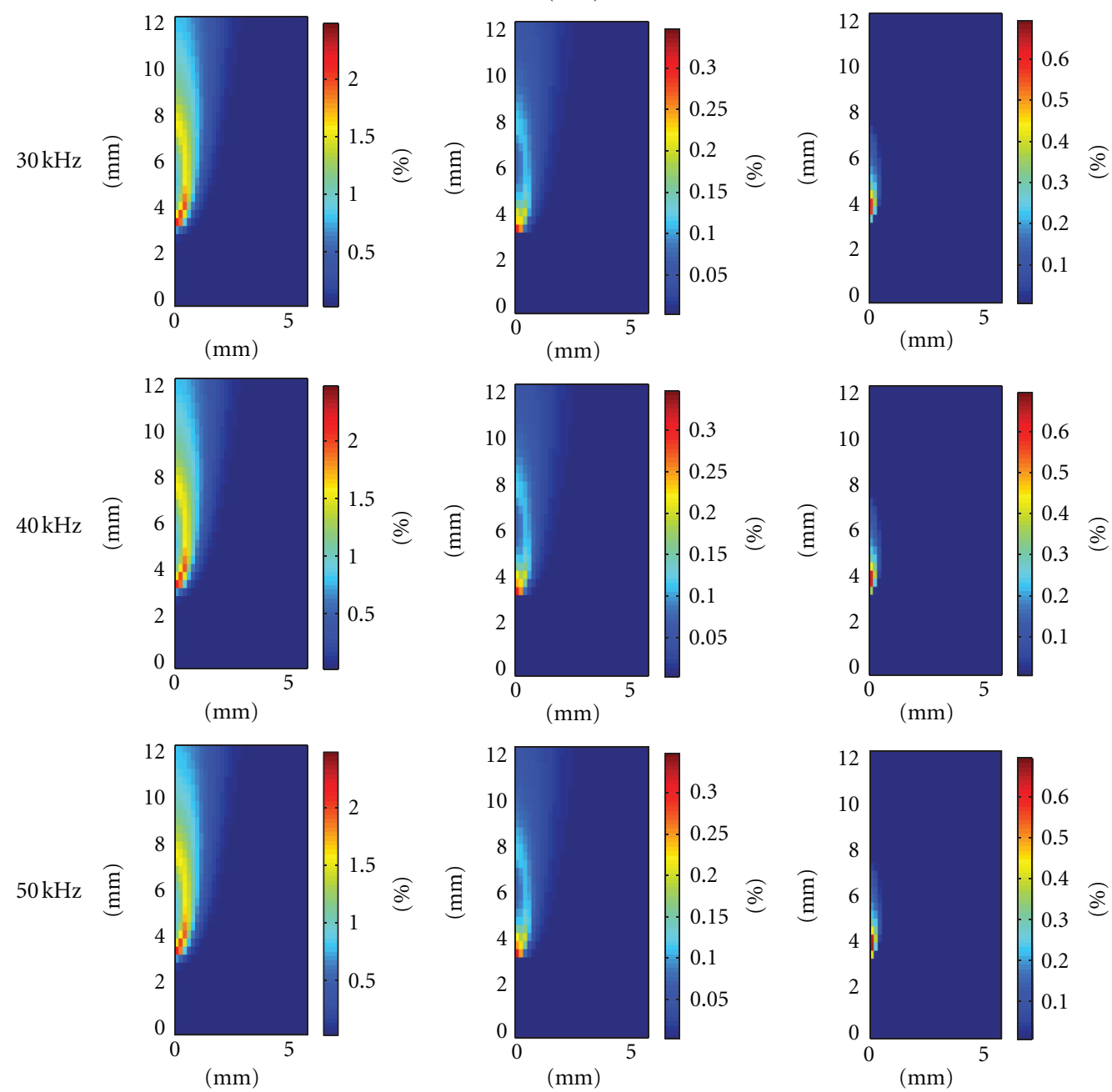

(a) $\mathrm{CO}$
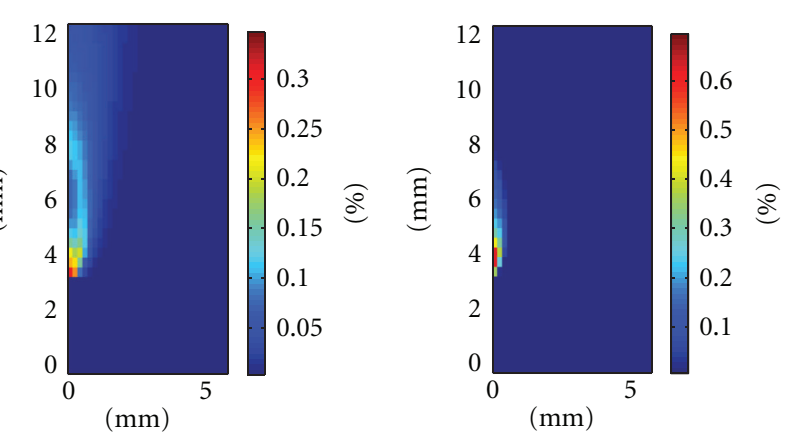

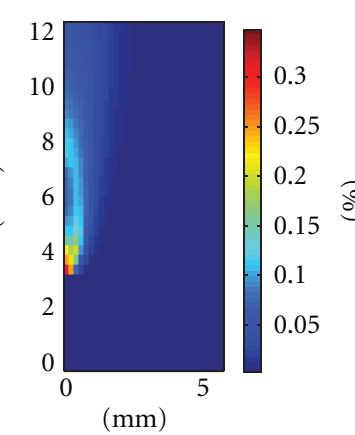

(b) $\mathrm{H}_{2}$

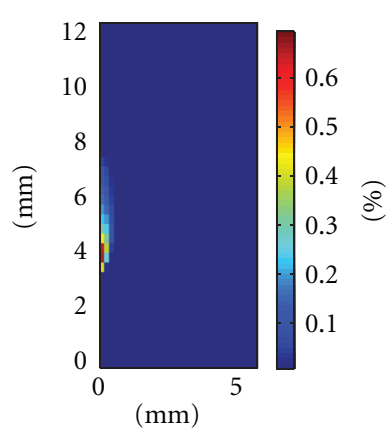

(c) $\mathrm{O}$

FIgURe 4: Quasi-steady state spatial distribution of (a) CO, (b) $\mathrm{H}_{2}$, and (c) $\mathrm{O}$ for different repetition rates of $10 \mathrm{kHz}, 20 \mathrm{kHz}, 30 \mathrm{kHz}, 40 \mathrm{kHz}$, and $50 \mathrm{kHz}$ at $9 \mathrm{~ns}$ pulse width. 

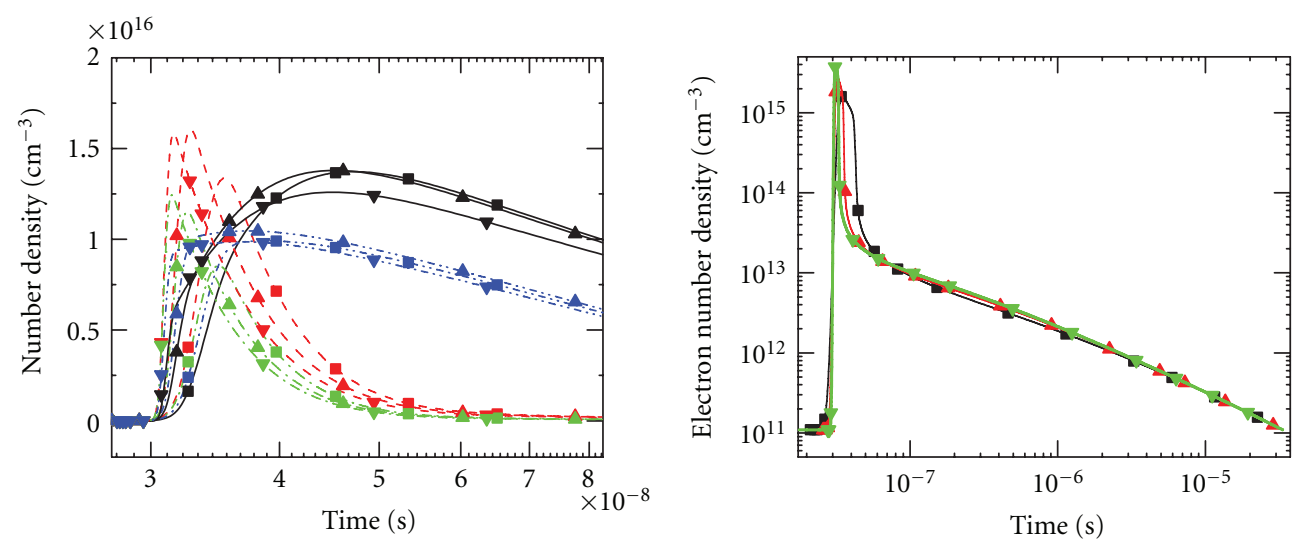

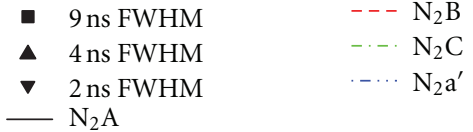

(a)

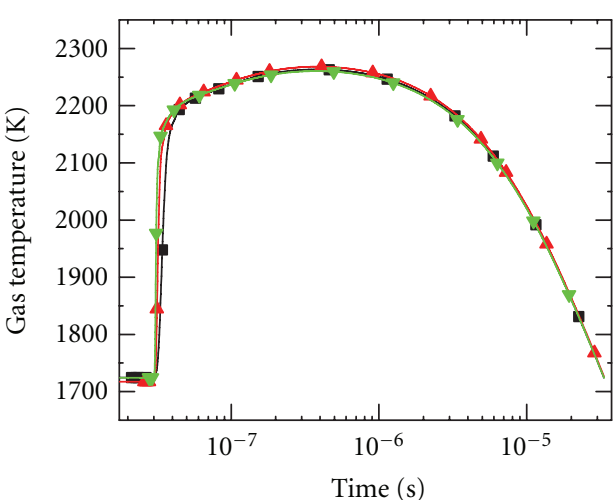

- 9ns FWHM

— 4 ns FWHM

$\rightarrow-2$ ns FWHM

(c)

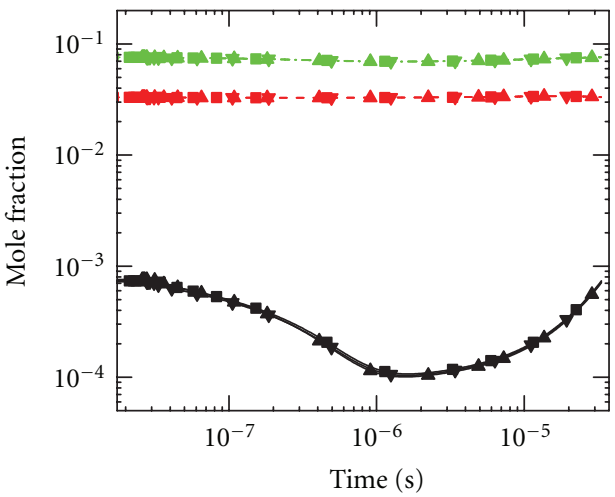

- 9 ns FWHM

- 4 ns FWHM

$-\mathrm{CH}_{4}$

- - $\mathrm{CO}_{2}$

-.. $\mathrm{H}_{2} \mathrm{O}$

(e) (b)

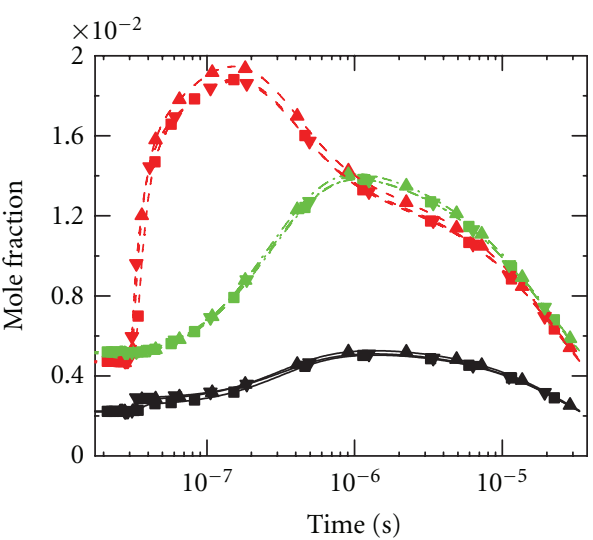

- 9 ns FWHM

- 4 ns FWHM

$-\mathrm{H}$

$\checkmark 2$ ns FWHM

(d)

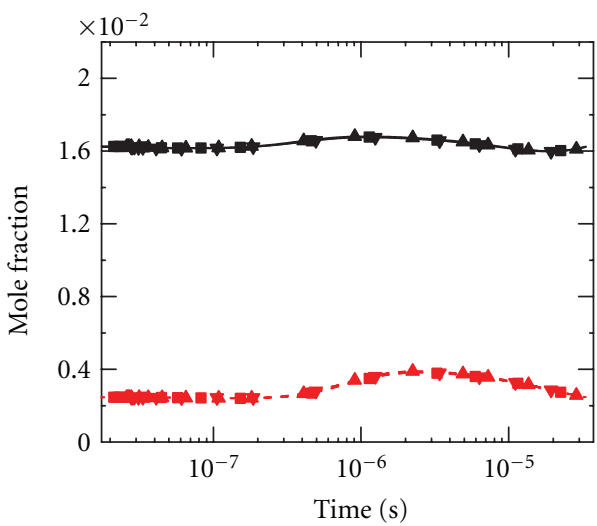

- 9 ns FWHM

$-\mathrm{CO}$

- 4 ns FWHM

$---\mathrm{H}_{2}$

> 2ns FWHM

(f)

Figure 5: Kinetic evolution of (a) excited electronic states of $\mathrm{N}_{2}\left(\mathrm{~A}, \mathrm{~B}, \mathrm{C}, \mathrm{a}^{\prime}\right)$, (b) electron, (c) gas temperature, (d) radicals $(\mathrm{O}, \mathrm{H}$, and $\mathrm{OH}$ ), (e) combustion major species $\left(\mathrm{CH}_{4}, \mathrm{CO}_{2}\right.$, and $\left.\mathrm{H}_{2} \mathrm{O}\right)$, and (f) minor species $\left(\mathrm{H}_{2}\right.$ and $\left.\mathrm{CO}\right)$ within the discharge region during a single period when the repetition rate is $30 \mathrm{kHz}$ and pulse widths are $9 \mathrm{~ns}, 4 \mathrm{~ns}$, and $2 \mathrm{~ns}$. 


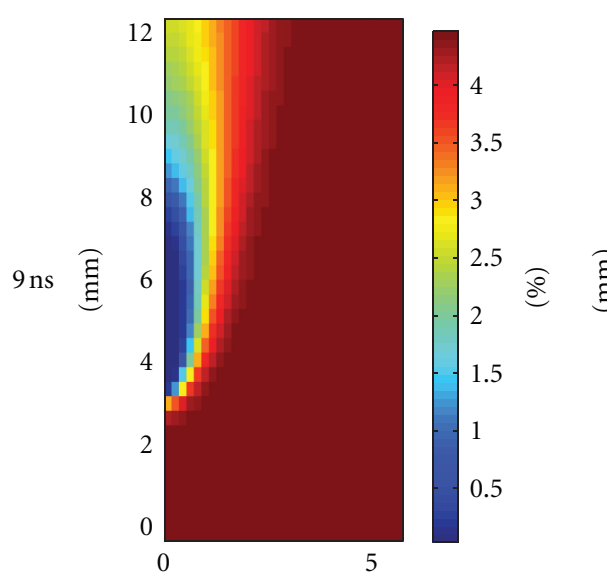

(mm)

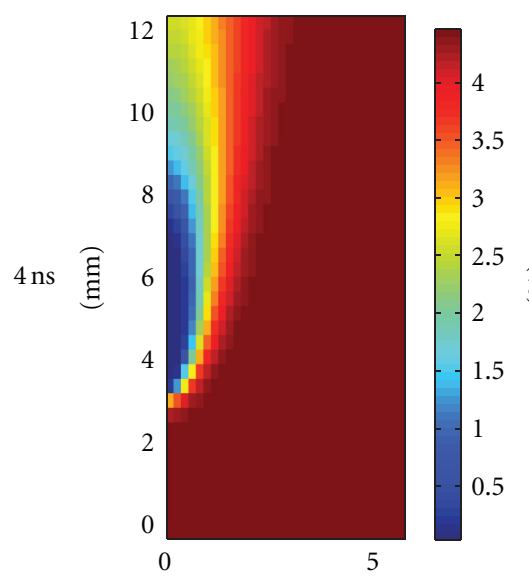

(mm)

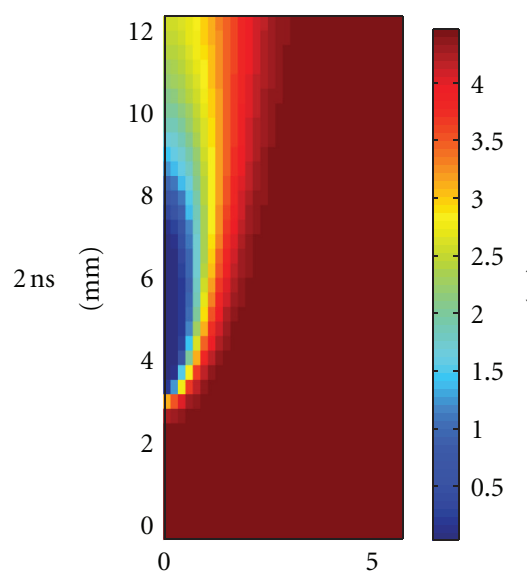

(mm)

(a) $\mathrm{CH}_{4}$

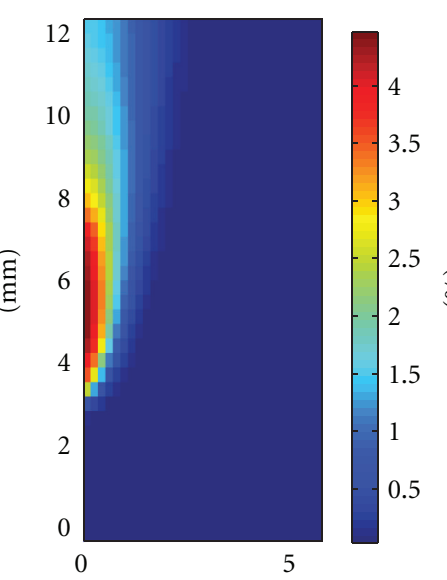

(mm)

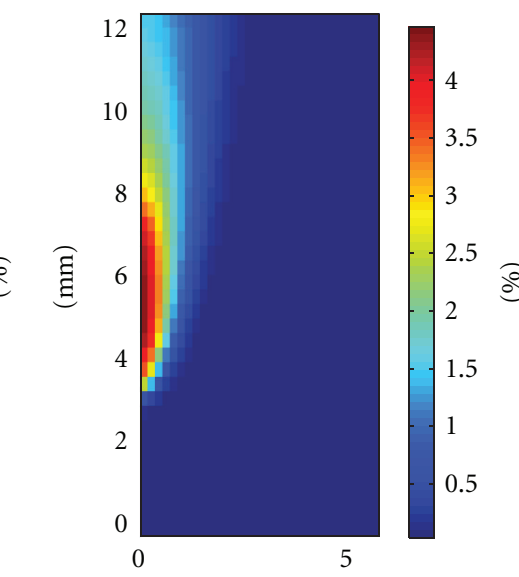

(mm)

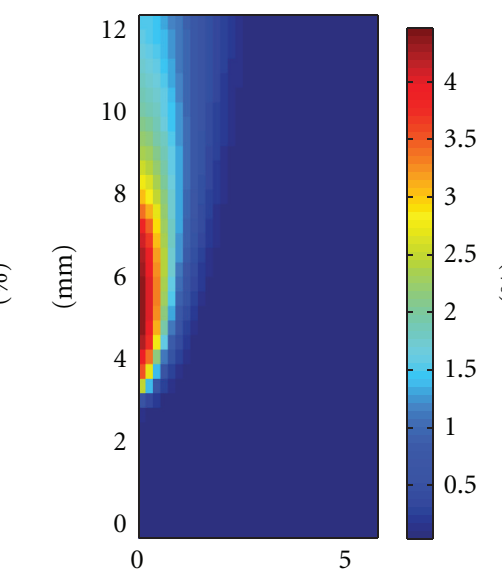

$(\mathrm{mm})$

(b) $\mathrm{CO}_{2}$

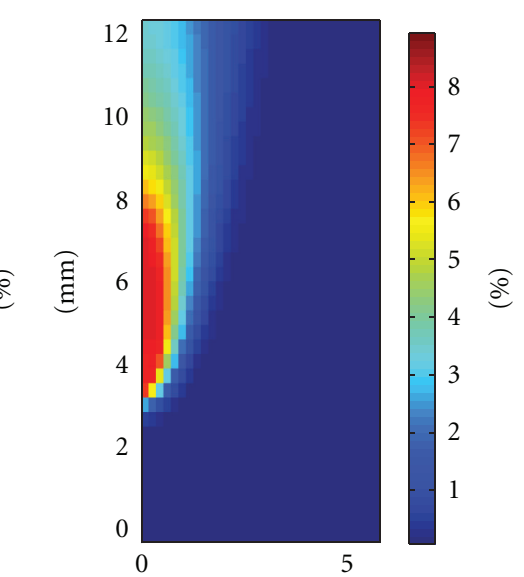

(mm)

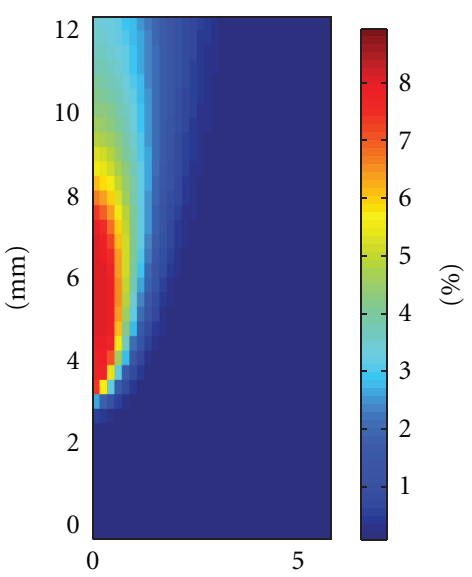

$(\mathrm{mm})$

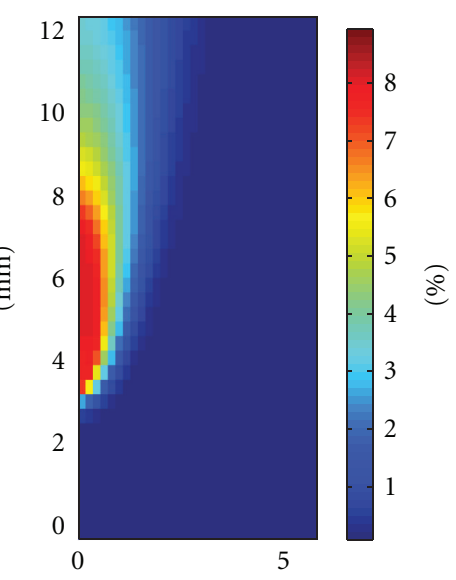

(mm)

(c) $\mathrm{H}_{2} \mathrm{O}$

FIGURE 6: Quasi-steady state spatial distribution of (a) $\mathrm{CH}_{4}$, (b) $\mathrm{CO}_{2}$, and (c) $\mathrm{H}_{2} \mathrm{O}$ for three different pulse widths of 9 ns, $4 \mathrm{~ns}$, and 2 ns at $30 \mathrm{kHz}$ repetition rate. 


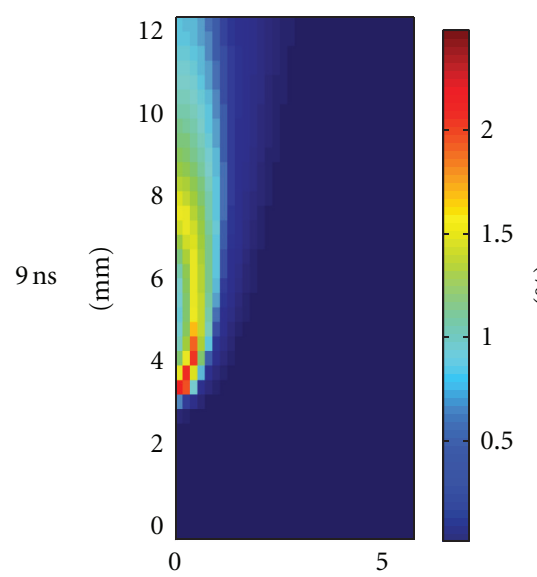

$(\mathrm{mm})$

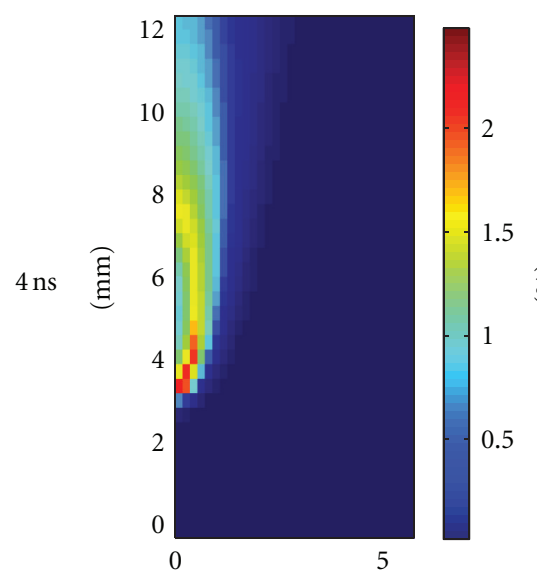

$(\mathrm{mm})$

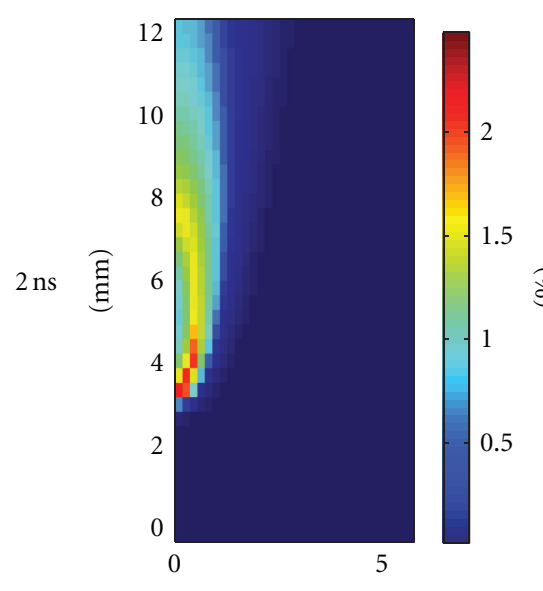

(mm)

(a) $\mathrm{CO}$

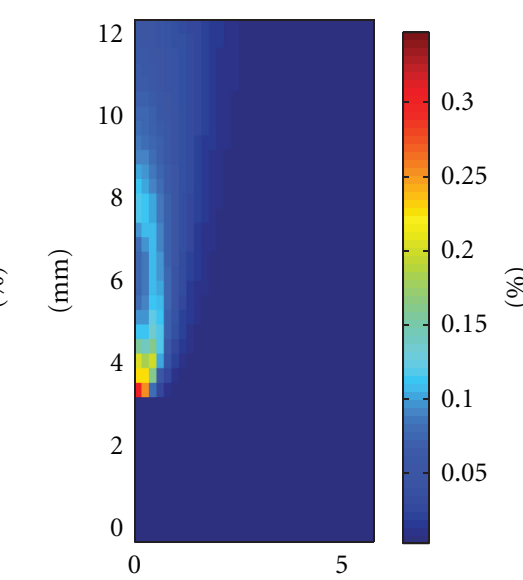

(mm)

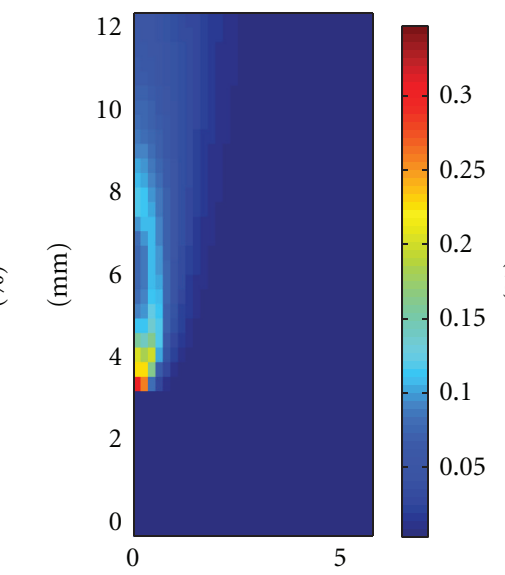

(mm)

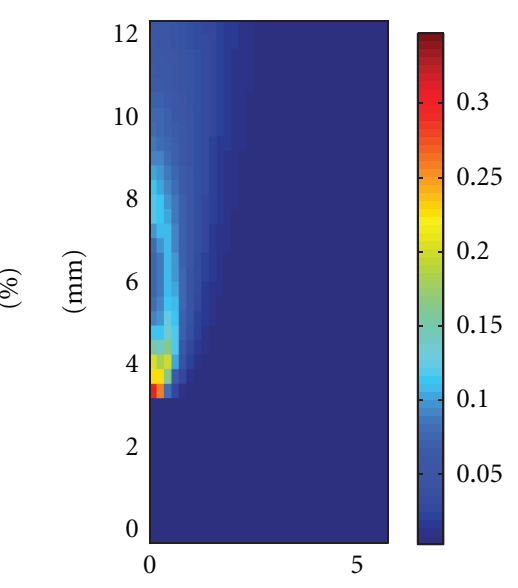

(mm)

(b) $\mathrm{H}_{2}$

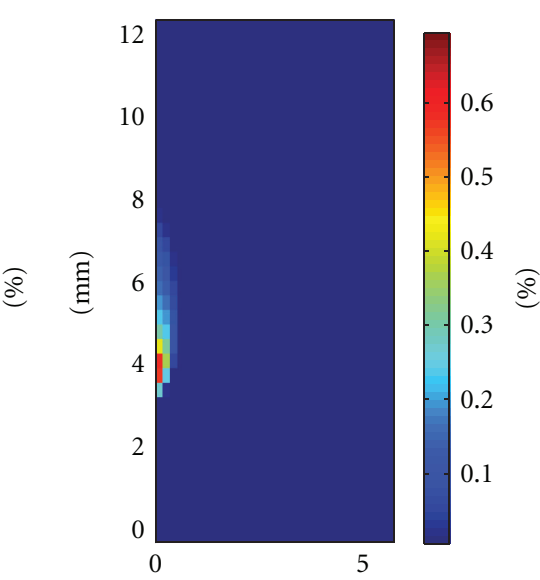

(mm)

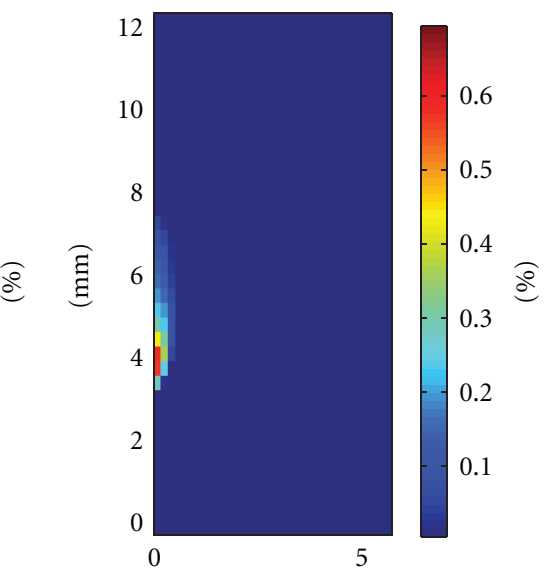

$(\mathrm{mm})$

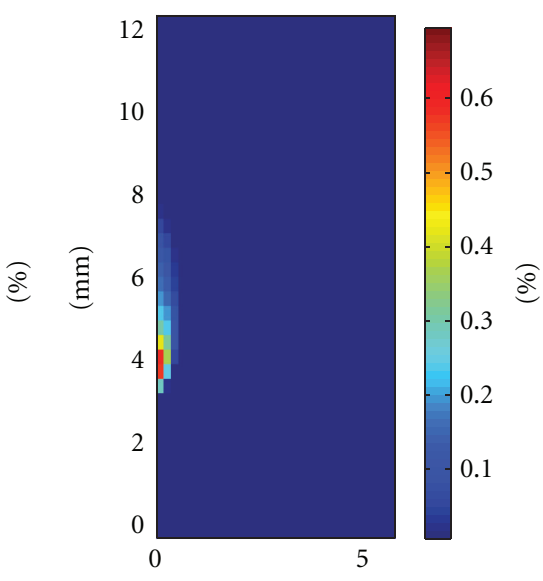

(mm)

(c) $\mathrm{O}$

Figure 7: Quasi-steady state spatial distribution of (a) $\mathrm{CO}$, (b) $\mathrm{H}_{2}$, and (c) $\mathrm{O}$ for three different pulse widths of $9 \mathrm{~ns}, 4 \mathrm{~ns}$, and $2 \mathrm{~ns}$ at $30 \mathrm{kHz}$ repetition rate. 
excited state species population required to keep the discharge region combusted (Figures 3(a), 3(b), and 3(c)), while the peak levels of the produced radicals (Figure 4(c)) are less important because they decay quickly to the thermally equilibrated values in the post-discharge region through radical recombination reactions. These recombination reactions eventually release heat energy to the stream. In essence, while radicals play some role in the kinetics, we find that the average power, irrespective of the mechanism through which heating takes place, is the critical factor on stabilizing combustion.

3.2. Results for Different Pulse Width Ranging from 9 ns to 2 ns. Simulations for different pulse widths corresponding to $9 \mathrm{~ns}$, $4 \mathrm{~ns}$, and $2 \mathrm{~ns}$ are compared, while maintaining constant average discharge power. The energy per pulse is $14 \mu$ J because the repetition rate is also kept constant, but the temporal energy density during the pulse is higher for the shorter pulse width. This is reflected in the higher reduced electric fields for shorter pulses. The fields are determined to be $328 \mathrm{Td}, 421 \mathrm{Td}$, and $535 \mathrm{Td}$ for $9 \mathrm{~ns}, 4 \mathrm{~ns}$, and $2 \mathrm{~ns}$ pulse widths, respectively. The detail kinetics within the discharge region is shown in Figure 5. Because of the higher temporal energy density for the shorter pulses, the shorter pulses result in larger peak electron number densities (Figure 5(b)). For excited electronic states of $\mathrm{N}_{2}$ (Figure 5(a)), more energized electrons during the shorter pulses populate the higher energy states. $\mathrm{N}_{2} \mathrm{C}$ is produced most when the pulse width is the shortest. However, this different degree of population between these states does not appear to lead to significant differences in the amounts of produced radicals such as $\mathrm{O}, \mathrm{H}$, and $\mathrm{OH}$ (Figure 5(d)). The results are very similar for all of the tested pulse widths, and the kinetic evolutions for minor species $\left(\mathrm{H}_{2}\right.$ and $\mathrm{CO}$, Figure $\left.5(\mathrm{f})\right)$ and major species $\left(\mathrm{CH}_{4}\right.$, $\mathrm{CO}_{2}$, and $\mathrm{H}_{2} \mathrm{O}$, Figure 5(e)) are found to be the same. This finding indicates that shorter pulses populate higher energy states with more preference but do not lead to a noticeably larger radical amount.

The quasi-steady states contours of major and minor combustion species are shown in Figures 6 and 7, respectively, for pulse widths of $9 \mathrm{~ns}, 4 \mathrm{~ns}$, and $2 \mathrm{~ns}$. The contours for $\mathrm{CH}_{4}, \mathrm{CO}_{2}, \mathrm{H}_{2} \mathrm{O}, \mathrm{CO}, \mathrm{H}_{2}$, and $\mathrm{O}$ correspond to Figures 6(a), 6(b), and 6(c) and Figures 7(a), 7(b), and 7(c), respectively. As seen in the figures, the contours are almost exactly the same for the three different pulse widths. This is expected since the discharge kinetics describing radical production (Figure 5) were also very similar. This again suggests that the average power is the defining factor on the chemistry, and little benefit is achieved by shortening the pulse into the nanosecond range.

\section{Conclusion}

The effect of repetition rate and pulse width on combustion stabilization for nanosecond repetitively pulsed discharges was investigated by computational simulations. In these simulations, the total average discharge power is kept constant. Since the lower repetition rates have larger pulse energy and a corresponding longer time between pulses, the gas temperature rises and the produced radicals were greater but their quasi-steady values were correspondingly lower than cases of higher repetition rate. However, in spite of this different degree of kinetic evolution, the contours for major and minor combustion species were found to be almost exactly the same and independent of repetition rate. Shortening the pulse widths while maintaining a constant average discharge power produced a higher peak population of excited electronic state species but the overall quasi-steady amounts were similar to all pulse widths and therefore the contours of the combustion products were also similar. From these simulations, we conclude that the average discharge power is found to be the determining factor on combustion stabilization and little if any benefit is obtained by varying the operation parameters such as the repetition rate and pulse width of nanosecond pulsed discharges over the range of conditions studied here.

\section{Acknowledgments}

This work is supported by the National Science Foundation and the Department of Energy through the NSF/DOE Partnership in Basic Plasma Science. M. S. Bak is also supported by a Stanford Graduate Fellowship.

\section{References}

[1] S. M. Starikovskaia, "Plasma assisted ignition and combustion," Journal of Physics D, vol. 39, no. 16, pp. R265-R299, 2006.

[2] M. S. Bak, H. Do, M. G. Mungal, and M. A. Cappelli, "Plasmaassisted stabilization of laminar premixed methane/air flames around the lean flammability limit," Combustion and Flame, vol. 159, no. 10, pp. 3128-3137, 2012.

[3] G. D. Stancu, F. Kaddouri, D. A. Lacoste, and C. O. Laux, "Atmospheric pressure plasma diagnostics by OES, CRDS and TALIF," Journal of Physics D, vol. 43, no. 12, pp. 124002124010, 2010.

[4] G. Pilla, D. Galley, D. A. Lacoste, F. Lacas, D. Veynante, and C. O. Laux, "Stabilization of a turbulent premixed flame using a nanosecond repetitively pulsed plasma," IEEE Transactions on Plasma Science, vol. 34, no. 6, pp. 2471-2477, 2006.

[5] M. A. Deminsky, I. V. Kochetov, A. P. Napartovich, and S. B. Leonov, "Modeling of plasma assisted combustion in premixed supersonic gas flow," International Journal of Hypersonics, vol. 1, no. 4, pp. 209-224, 2010.

[6] C. H. Kruger, C. O. Laux, L. Yu, D. M. Packan, and L. Pierrot, "Nonequilibrium discharges in air and nitrogen plasmas at atmospheric pressure," Pure and Applied Chemistry, vol. 74, no. 3, pp. 337-347, 2002.

[7] D. Z. Pai, D. A. Lacoste, and C. O. Laux, "Transitions between corona, glow, and spark regimes of nanosecond repetitively pulsed discharges in air at atmospheric pressure," Journal of Applied Physics, vol. 107, no. 9, Article ID 093303, 15 pages, 2010.

[8] A. Kazakov and M. Frenklach, "Reduced reaction sets based on GRI-Mech 1.2," http://www.me.berkeley.edu/drm/.

[9] M. Frenklach, H. Wang, C.-L. Yu et al., http://www.me.berkeley.edu/gri_mech/.

[10] A. Burcat, Third Millennium Ideal Gas and Condensed Phase Thermochemical Database for Combustion, TAE 867, Technion-Israel Institute of Technology, 2001. 
[11] G. J. M. Hagelaar and L. C. Pitchford, "Solving the Boltzmann equation to obtain electron transport coefficients and rate coefficients for fluid models," Plasma Sources Science and Technology, vol. 14, no. 4, pp. 722-733, 2005.

[12] A. C. Hindmarsh, P. N. Brown, K. E. Grant et al., "SUNDIALS: suite of nonlinear and differential/algebraic equation solvers," ACM Transactions on Mathematical Software, vol. 31, no. 3, pp. 363-396, 2005.

[13] http://www.open-mpi.org/.

[14] Y. Saad and M. H. Schultz, "GMRES: a generalized minimal residual algorithm for solving nonsymmetric linear systems," SIAM Journal on Scientific and Statistical Computing, vol. 7, no. 3, pp. 856-869, 1986. 

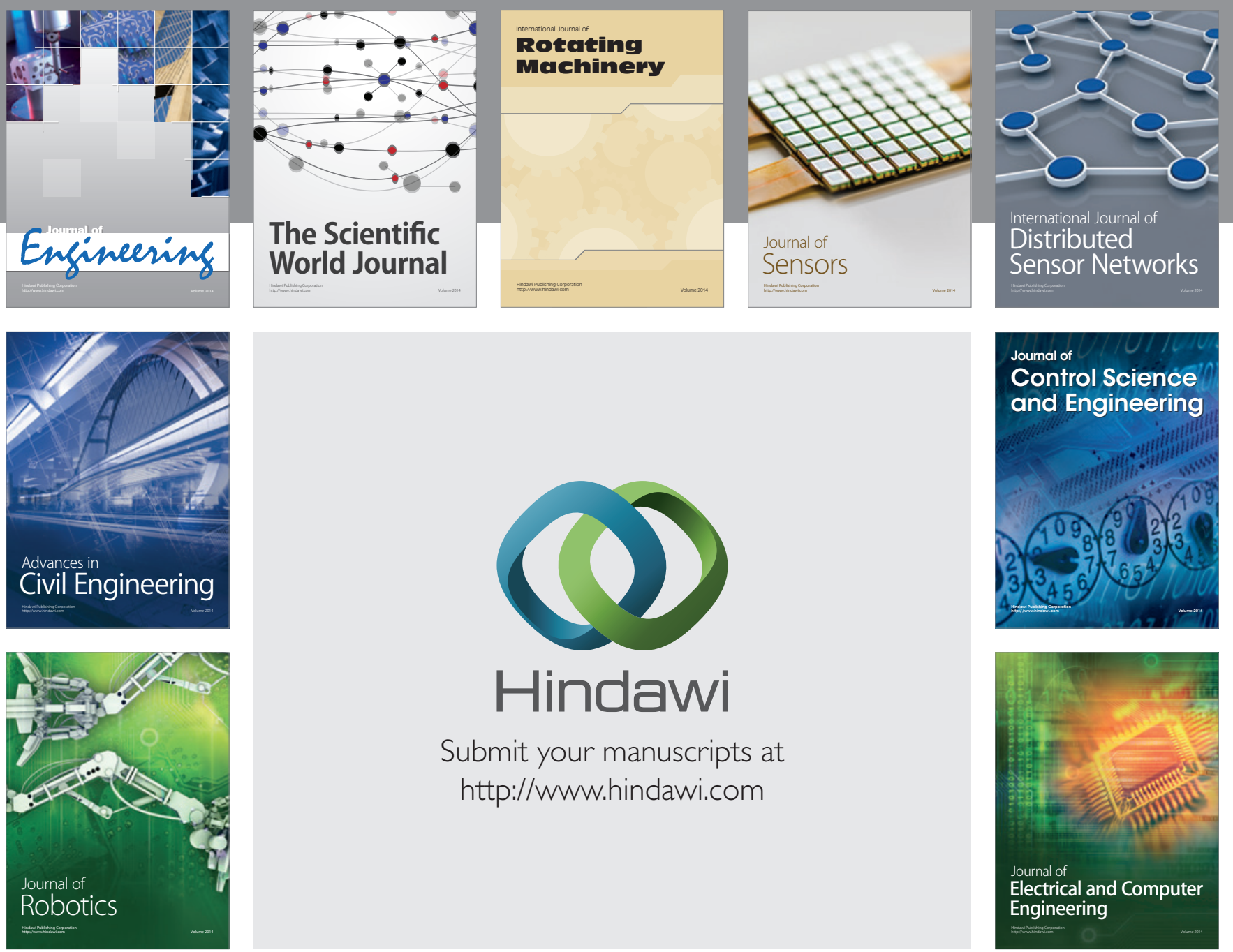

Submit your manuscripts at

http://www.hindawi.com
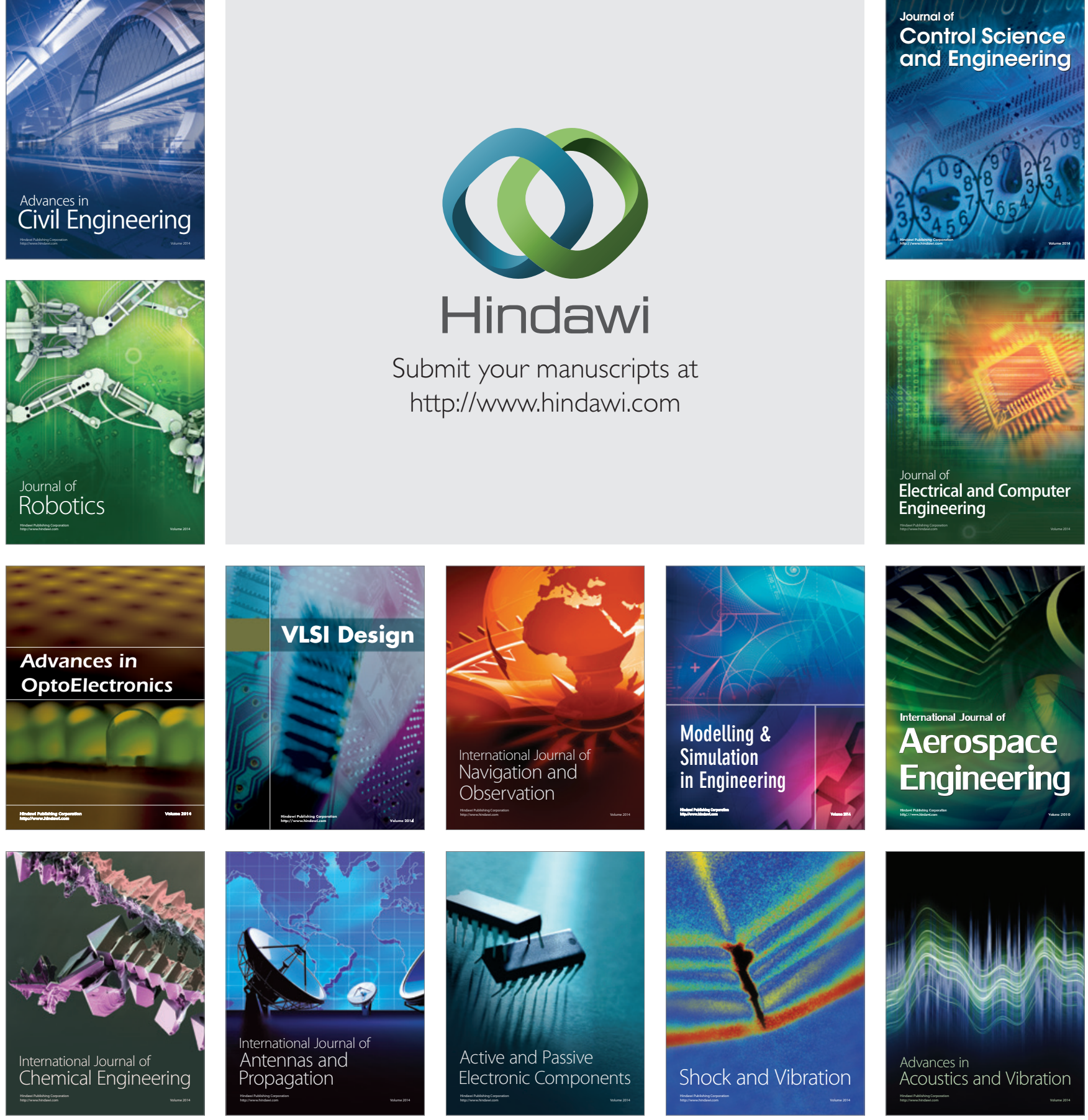